\title{
Modelling and Validation of Automotive Engine Fuelled with Palm Oil Biodiesel
}

\author{
M. N. Azuwir, M. Z. Abdulmuin, and A. H. Adom
}

\begin{abstract}
This paper presents the Black-box modelling of automotive diesel engine fuelled with palm oil biodiesel (Palm Oil Methyl Ester). The aim of the work described in this paper is to obtain linear dynamic model of the palm oil biodiesel from test data. Assuming a discrete time form for the system model, an Autoregressive Moving Average with eXogenous input (ARMAX) model structures was selected in this work. A Pseudo-Random Binary Sequence (PRBS) with maximum lengths sequence of 31 has been used as the test input signal to the engine at the speed range around $2100 \mathrm{rpm}$. The input and output signals were interfaced to the plant via Matlab programming. Recursive estimation algorithm, Recursive Extended Least Squares (RELS), is used to estimate the model parameters. Finally, model validation was done by comparing the output predicted by the model against the measured output and also by error analysis. The mathematical model developed in this study present an analysis and simulation tools of engine dynamic system that forms the foundation for a systematic approach to the analysis, simulation and synthesis of the automotive palm oil biodiesel engine control systems. The model derived in this work is intended for the development of self-tuning engine speed controller in future work.
\end{abstract}

Index Terms - Identification; Modeling; Biodiesel; Palm oil biodiesel

\section{INTRODUCTION}

One of the key ingredients to any economic activity is energy. The energy demand in developing countries will continuously rise enormously especially in industrialized countries. By the year 2020, as inspired by the Wawasan 2020, Malaysia will become a developed country. Therefore, Malaysia needs to make sure its energy supply is adequate to accelerate its economic development. As an alternative to fossil fuel, the use of biofuel will reduce the dependency on depleting fossil fuel. The National Biofuel Policy, launched on 21 March 2006, envision that biofuel will be enhancing the nation's prosperity and well-being by the five strategic trusts: Biofuel for transportation, Biofuel for industry, Biofuel for technologies, Biofuel for export, Biofuel for cleaner environment [1].

Studies related to alternative energy from palm waste industry in Malaysia have been rigorously done since the late 1990s. For example, Mahlia et al. [2] studied the usage of fiber and shell obtained from the processing of palm oil

Manuscript received May 30, 2011; revised November 11, 2011. This work was supported in part by the Universiti Malaysia Perlis.

M. N. Azuwir and M. Z. Abdulmuin are with School of Manufacturing Engineering, Universiti Malaysia Perlis, Kampus Pauh Putera, 02600 Arau, Perlis, Malaysia (e-mail: azuwir@unimap.edu.my, zakimuin@unimap. edu.my).

A. H. Adom is with School of Mechatronics Engineering, Universiti Malaysia Perlis, Kampus Pauh Putera, 02600 Arau, Perlis, Malaysia (email:abdhamid@unimap.edu.my). as fuel for the boiler. They even extend their studies toward the development of a dynamic model and simulation of the palm waste boiler [3]. While Masjuki et al [4] studied the performance and tribological characteristics of an indirect diesel engine operation on palm oil methyl esters and its emulsion.

A very comprehensive review and importance of biodiesel as transportation fuel was done by Balat and Balat [5] and Demirbas [6]. Biodiesel has demonstrated a number of promising characteristics and has become more attractive recently because of its environmental benefits. Agarwal [7] reviews the performance and emission of biodiesel in compression ignition engines, combustion analysis, wear performance on long term engine usage and economic feasibility.

Research and development efforts have demonstrated that palm oil biodiesel (palm oil methyl esters) is a good source for energy production [8],[9]. Generally, palm oil biodiesel exhibits fuel properties comparable to those of petroleum diesel, refer to Table I and Table II, and can be used directly in unmodified diesel engines

Several studies have been done on the performance of the biofuel as a substitute fuel for unmodified diesel engine [1014]. However, studies on biodiesel engine modeling and control are scanty. Among the foremost studies are those of Ganapathy et al. [15] who studied a methodology for thermodynamic model analysis of biodiesel engine and Ramadhas et al. [16] who developed a theoretical model and analyzed the performance characteristics of compression ignition engine fuelled by biodiesel and its blends.

TABLE I: Fuel CharaCteristics OF METHYl Esters OF CRUDE PALM OIL (CPO) AND CRUDE PALM STERIN (CPS)

\begin{tabular}{|c|c|c|c|}
\hline Test & $\begin{array}{c}\text { Methyl Esters } \\
\text { of CPO } \\
\end{array}$ & $\begin{array}{c}\text { Methyl Esters } \\
\text { of CPS } \\
\end{array}$ & $\begin{array}{c}\text { Malaysian } \\
\text { Diesel } \\
\end{array}$ \\
\hline $\begin{array}{l}\text { Specific gravity } \\
\text { ASTM D } 1290\end{array}$ & $\begin{array}{c}0.8700 @ 7.5^{\circ} \mathrm{F} \\
\end{array}$ & 0.8713 & $\begin{array}{c}0.8330 @ \\
60.0^{\circ} \mathrm{F}\end{array}$ \\
\hline Colour (visual) & Reddish & Orange & Yellow \\
\hline $\begin{array}{l}\text { Sulphur content ( } \% \\
\text { wt.) IP } 242\end{array}$ & $<0.04$ & $<0.04$ & 0.10 \\
\hline $\begin{array}{l}\text { Viscosity@40 } 40^{\circ} \mathrm{C} \\
\text { (cSt) ASTM D445 }\end{array}$ & 4.5 & 4.6 & 4.0 \\
\hline $\begin{array}{l}\text { Pour point }\left({ }^{\circ} \mathrm{C}\right) \\
\text { ASTM D97 }\end{array}$ & 16.0 & 17.0 & 15.0 \\
\hline $\begin{array}{l}\text { Distillation: final } \\
\text { recovery (ml) ASTM } \\
\text { D86 }\end{array}$ & 98.0 & 98.5 & - \\
\hline $\begin{array}{l}\text { Gross heat of } \\
\text { combustion }(\mathrm{kJ} \mathrm{kg-1)} \\
\text { ASTM D2382 }\end{array}$ & 40135 & 39826 & 45800 \\
\hline $\begin{array}{l}\text { Flash point }\left({ }^{\circ} \mathrm{C}\right) \\
\text { ASTM D93 }\end{array}$ & 174 & 165 & 98 \\
\hline $\begin{array}{l}\text { Conradson carbon } \\
\text { residue (\% wt.) } \\
\text { ASTM D198 }\end{array}$ & 0.02 & 0.05 & 0.14 \\
\hline
\end{tabular}

SOURCE: CHOO, Y M ET AL. 
TABle II: Cetane Number of CRude Palm Oil (CPO) Methyl Esters, PETROLEUM DieSEL (FROM EUROPE) AND THEIR BLEND

\begin{tabular}{ccc}
\hline \hline $\begin{array}{c}\text { CPO Methyl Esters } \\
(\%)\end{array}$ & $\begin{array}{c}\text { Petroleum Diesel } \\
(\%)\end{array}$ & $\begin{array}{c}\text { Cetane } \\
(\text { ASTM D613) }\end{array}$ \\
\hline 100 & 0 & 62.4 \\
0 & 100 & 37.7 \\
5 & 95 & 39.2 \\
10 & 90 & 40.3 \\
15 & 85 & 42.3 \\
20 & 80 & 44.3 \\
30 & 70 & 47.4 \\
40 & 60 & 50.5 \\
\hline \hline
\end{tabular}

SOURCE: CHOO, Y M ET AL.

Optimization of the internal combustion engine performance fuelled with biodiesel can only be achieved if the engine controller are carefully designed and developed. In order to realize a reliable and an efficient automotive engine fuel with biodiesel, researchers must truly understand the behavior of the engine. The modeling of the engine to represent the best approximation of the system is very crucial to ensure good and reliable result. Thus, derivation of the mathematical model that best represent the engine must be constructed preceding the controller development. With this technique, perturbation studies, sensitivity and error analysis and system response measurement can be readily performed on such model, and the effect of such system modifications can be demonstrated simply [17]. The success of controller development via mathematical model is that the model must be highly accurate.

The purpose of this paper is to derive a stochastic mathematical model of an automotive palm oil biodiesel engine at medium speed range (around $2100 \mathrm{rpm}$ ) using a black-box modeling technique. An Autoregressive Moving Average with eXogenous input (ARMAX) model was selected as the system model structure. A Recursive Extended Least Squares technique is used to estimate the model parameters. Finally, model validation was done by comparing the output predicted by the model against the measured output and also by error analysis.

\section{EXPERIMENT DESIGN AND SETUP}

The system under consideration is a 2000cc, Direct Injection, DOHC Mitsubishi Diesel Engine. The engine is mounted on a test bed with an eddy current dynamometer braking unit. The dynamometer is linked to the engine with a shaft. The input signal is transmitted through an auto throttle servo actuator that provide an automatic throttle control by receiving a signal of 0 to $10 \mathrm{~V}$, corresponding to 0 to $100 \%$ throttle opening control. It has an accuracy of \pm $0.1 \%$ with a linear sensor attached directly to the throttle assembly with no backlash errors. The engine speed was transmitted by optical encoder also with a signal range of 0 to $10 \mathrm{~V}$.

The system identification problem is to estimate a model of a system based on observed input-output data. The procedure to determine a model of a dynamical system from observed input-output data involves four basic ingredients:

1. The input-output data

2. The model structure

3. The identification method

4. Model validation
System identification is the process of determining the mathematical equations that govern the model's dynamics. It consists of repeatedly selecting a model structure, computing the best model in the structure, and evaluating this model's properties to see if they are satisfactory. The process flow can be summarized as below:

i. Design an experiment for data collection - the purpose of the experiment is to collect several sets of inputoutput data over its entire range of operating points. The idea is to vary the input signal and observes the response of the output signal.

ii. Select and define a model structure - a model structure is a set of mathematical equations from which the final mathematical model will be derived. It could be a linear or nonlinear model.

iii. Parameter estimation - once the model has been selected a parameter estimation technique will be implemented for model fitting.

iv. Model validation - validate the mathematical model derived in the previous step.

v. Repeat the process until good model is achieved.

\section{A. Excitation Signal}

A PRBS signal with Maximum Length Sequences (MLS) characteristics was selected as the input signal injected to the plant for identification purposes. The PRBS state can change only at discrete intervals of time, $\Delta t$ which is also known as bit interval. PRBS sequence is periodic with period, $T=N^{*} \Delta t$ where $N=$ sequence length. Pseudorandom binary sequence can be generated by means of a serial-input shift register with feedback using exclusive-OR gate. The signal is not truly random because the sequence repeats itself every $2^{n}-1$ bit intervals for an n-bit shift register. The sequence length is related to the number of registers through the following equation:

$$
N=2^{n}-1
$$

where $n$ is the number of registers.

In this experiment, the signals are generated by a computer program using the exclusive-OR and modulo-2 addition with $n=5$. As a rule of thumb in designing the PRBS signal, the clock period $\Delta t$ is normally chosen to be approximately in the range of a fifth to a half of the output response time constant $\left(T_{c}\right.$, $)$ i.e.

$$
\Delta t=(0.2 \text { to } 0.5) \times T_{C}
$$

\section{B. Model Structure}

In this work, the system is assumed as a discrete linear model. In general, the control input $u(t)$ and the output of the system $y(t)$ can be expressed in the discrete time function form

$$
A y(t)=B u(t-1)+C e(t)
$$

where $e(t)$ is the noise signal and

$$
\begin{aligned}
& A=1+a_{1} z^{-1}+\ldots \ldots \ldots \ldots+a_{n_{a}} z^{-n_{a}} \\
& B=b_{0}+b_{1} z^{-1}+\ldots \ldots \ldots .+b_{n_{b}} z^{-n_{b}} \\
& C=1+c_{1} z^{-1}+\ldots \ldots \ldots .+c_{n_{c}} z^{-n_{c}}
\end{aligned}
$$

The polynomial coefficients of Eq.(4-6) are treated as the parameters to be determined by estimation. Thus, it is easier 
to write Eq.(3) using the backshift interpretation of $z^{-1}$ and write the equation in the form

$$
y(t)=\mathbf{x}^{T}(t) \boldsymbol{\theta}+e(t)
$$

where $\boldsymbol{\theta}$ is the vector of unknown parameters,

$$
\boldsymbol{\theta}^{T}=\left[-a_{1}, \ldots .,-a_{n_{a}}, b_{0}, \ldots \ldots . ., b_{n_{b}}, c_{1}, \ldots, c_{n_{c}}\right]
$$

and $\mathbf{x}(\mathbf{t})$ is a regression vector consist of measured input and output variables and also the noise terms,

$$
\begin{aligned}
\mathbf{x}(\mathbf{t})= & {\left[y(t-1), \ldots ., y\left(t-n_{a}\right), u(t-1), \ldots, u\left(t-n_{b}-1\right),\right.} \\
& \left.e(t-1), e(t-2), \ldots . ., e\left(t-n_{C}\right)\right]
\end{aligned}
$$

The model considered in this study is the ARMAX model which includes the noise term in the system output of Eq. (3). In order to estimate the polynomial parameter $C$, the value of $e(t-1), \ldots \ldots e\left(t-n_{C}\right)$ is required but $e(t)$ is not measurable. Therefore, $e(t)$ is replaced by the prediction error $\mathcal{E}(t)$.

$$
\varepsilon(t)=y(t)-\boldsymbol{\varphi}^{\mathbf{T}} \hat{\boldsymbol{\theta}}(t-1)
$$

where

$$
\begin{gathered}
\widehat{\boldsymbol{\theta}}=\left[-\widehat{a}_{1}, \ldots,-\widehat{a}_{n_{a}}, \widehat{b}_{0}, \ldots, \widehat{b}_{n_{b}}, \widehat{c}_{1}, \ldots, \widehat{c}_{n_{C}}\right] \\
\boldsymbol{\varphi}^{\mathbf{T}}(t)=\left[y(t-1), \ldots, y\left(t-n_{a}\right), u(t-1), \ldots .\right. \\
\left.. ., u\left(t-n_{b}-1\right), \varepsilon(t-1), \ldots ., \varepsilon\left(t-n_{C}\right)\right]
\end{gathered}
$$

The ARMAX model structure selected in this study is defined as:

$$
y(t)=\frac{\widehat{b}_{1} z^{-1}}{1+\widehat{a}_{1} z^{-1}+\widehat{a}_{2} z^{-2}} u(t)+\frac{\left(1+\widehat{c}_{1} z^{-1}\right)}{1+\widehat{a}_{1} z^{-1}+\widehat{a}_{2} z^{-2}} \varepsilon(t)
$$

\section{Parameter Estimation}

The recursive least squares technique allows significant saving in the computation. Instead of recalculating the least squares estimate in its entirety, requiring the storage of all previous data, it merely stores the 'old' estimate calculated at time $\mathrm{t}$, denoted by $\hat{\boldsymbol{\theta}}(t)$, and to obtain the 'new' estimate $\hat{\boldsymbol{\theta}}(t+1)$ by an updating step involving the new data only. The iterative process of recursive parameter estimation can be visualized as shown in Fig. 1.

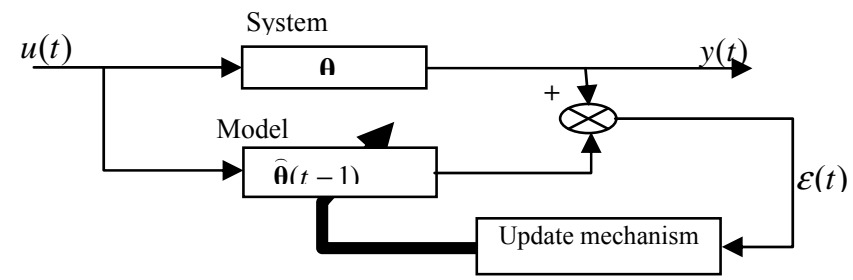

Fig. 1. Iterative process of recursive parameter estimation

The aim is to select a value of $\hat{\boldsymbol{\theta}}(t)$ so that the modeling error is minimized according to the sum of squares of errors:

$$
J=\sum_{t=1}^{N} \hat{e}^{2}(t)=\hat{\mathbf{e}}^{\mathbf{T}} \widehat{\mathbf{e}}
$$

The algorithms implemented for parameters estimation of the models under study is summarized as follows [18]:

At time step $(t+1)$ :

1) Form $\varphi(t+1)$ using the new data $u(t+1), y(t+1)$ and $\boldsymbol{\varepsilon}(t+1)=y(t+1)-\boldsymbol{\varphi}^{T}(t+1) \hat{\boldsymbol{\theta}}(t)$.
2) Form $\mathbf{P}(t+1)$ using $\mathbf{P}(t+1)=\mathbf{P}(t)\left[I_{m}-\frac{\boldsymbol{\varphi}(t+1) \boldsymbol{\varphi}^{\mathrm{T}}(t+1) \mathbf{P}(t)}{1+\boldsymbol{\varphi}^{\mathrm{T}}(t+1) \mathbf{P}(t) \boldsymbol{\varphi}(t+1)}\right]$.

3) Update $\hat{\boldsymbol{\theta}}(t), \hat{\boldsymbol{\theta}}(t+1)=\hat{\boldsymbol{\theta}}(t)+\mathbf{P}(t+1) \boldsymbol{\varphi}(t+1) \boldsymbol{\varepsilon}(t+1)$.

This algorithm is used to estimate the system parameters $\hat{a}_{1}, \hat{a}_{2}, \hat{b}_{1}$ and $\hat{c}_{1}$ in Eq. (13).

\section{Model Validation}

The model derived in this study was validated by plotting the output predicted by the model and comparing it with the measured output. The quality of the identified model is determined by the error between the measured and the predicted value.

\section{E. Experimental Setup}

For identification purposes, a Matlab program is written to generate the PRBS signals that fulfill the condition of persistent. The palm oil biodiesel engine is first run at a steady-state speed value before the input-output data were collected. A computer is interfaced to the actuator (auto throttle) and the speed sensor via an Agilent U2351A Multifunction DAQ. See Fig. 2.

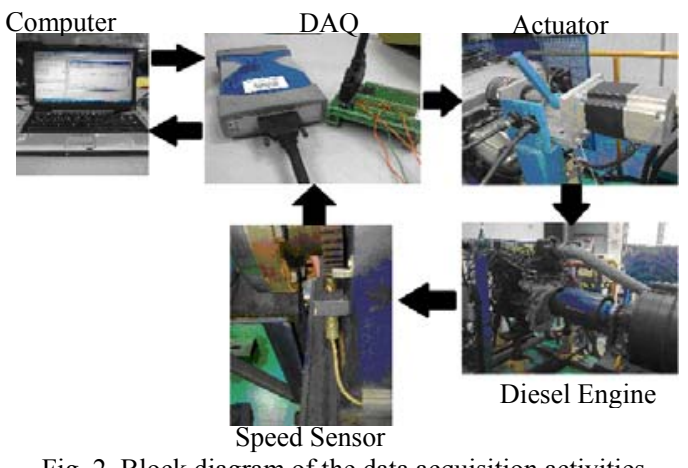

Fig. 2. Block diagram of the data acquisition activities.

In this experiment, a PRBS signal with maximum length sequence of 31 with time period of 1 second and sampling time of 0.17 second was used during data collection for engine modeling at the speed range of around $2100 \mathrm{rpm}$. Starting from steady-state conditions, a sequence of input signals is injected to excite the actuator. Two sets of realtime data were collected from the palm oil biodiesel engine test-bed. Each set consists of 720 data. The first set was used for model parameters estimation and identification activities while the second set of data used for model validation. Fig. 3 shows the engine speed response during the identification experiment when the PRBS signal was injected to the actuator from the computer.
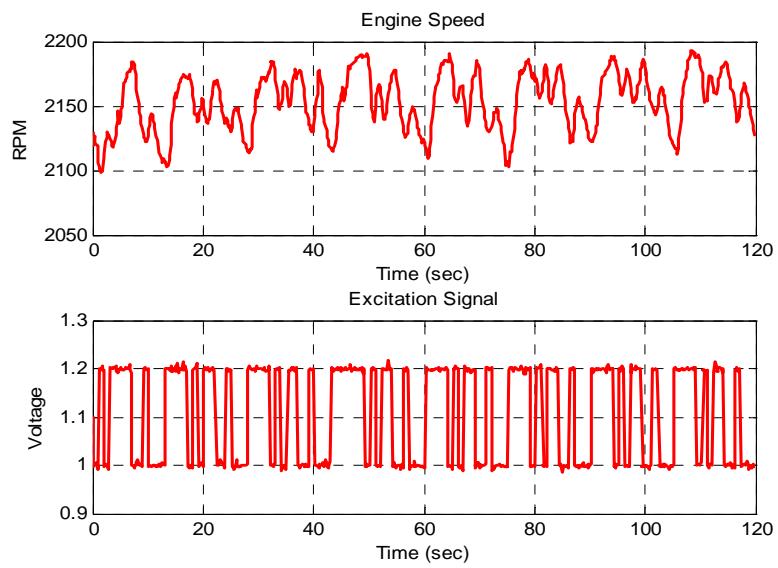

Fig. 3. Input and output signals for black box identification. 


\section{RESULTS AND DiscUSSIONS}

The iterative parameter estimation algorithm used in these experiments allowed the estimation of engine model of the system to be updated at each sample interval. The estimation of the model parameters significantly depends on the choices of initial values for data vector, parameter vector and covariance matrix $(\mathrm{P})$ at the first step. The experimental initial conditions designed in this study have successfully calculated the values of $a_{1}, a_{2}, b_{1}, c_{1}$ in less than 30 iterations. Fig. 4 shows the identification process of the diesel engine. In these figures, it can be clearly seen that the model predicted outputs are closed to those of the measured engine speed values.

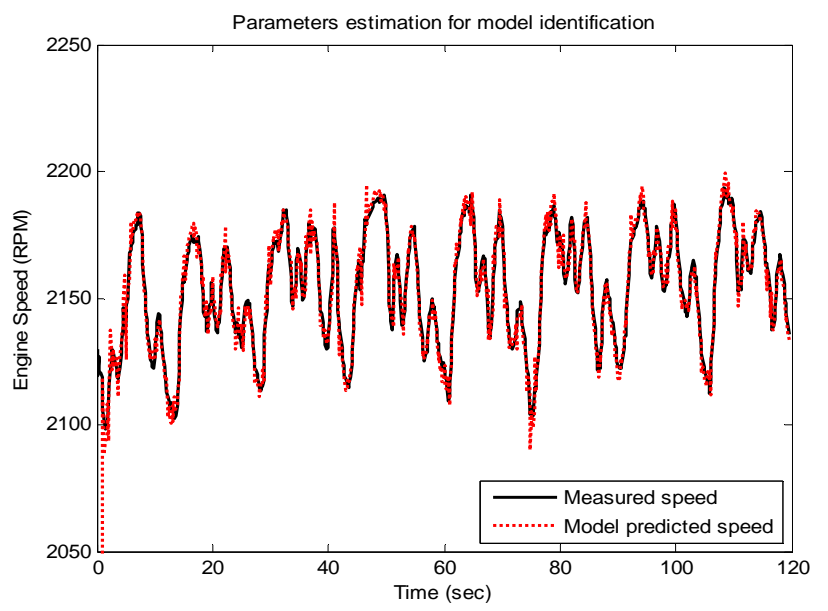

Fig. 4. Model identification.

The convergence of the all parameters is illustrated in Fig. 5. Almost all model parameters converged to a stable value in less than ten seconds. The parameters estimated for each model structure are shown in Table III.
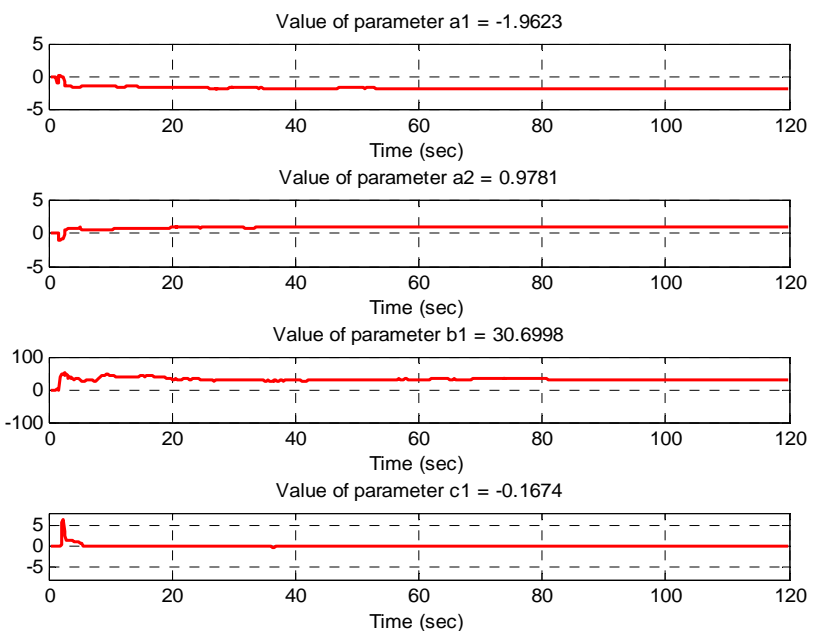

Fig. 5. Estimated model parameters value.

TABLE III: COMPARISON OF PARAMETERS FOR EACH MODEL

\begin{tabular}{lcccc}
\hline \hline $\begin{array}{l}\text { Model } \backslash \\
\text { Parameter }\end{array}$ & $\hat{a}_{1}$ & $\hat{a}_{2}$ & $\hat{b}_{1}$ & $\hat{c}_{1}$ \\
\hline ARMAX & -1.9623 & 0.9781 & 30.6998 & -0.1674 \\
\hline \hline
\end{tabular}

The estimated ARMAX model for the palm oil biodiesel engine derived in this study is:

$$
y(t)=\frac{30.6998 z^{-1}}{1-1.9623 z^{-1}+0.9781 z^{-2}} u(t)+\frac{\left(1-0.1674 z^{-1}\right)}{1-1.9623 z^{-1}+0.9781 z^{-2}} \varepsilon(t)
$$

The predicted output of ARMAX model mentioned above is then plotted against the second set of measured data for validation purposes. From Fig. 6, it can be seen that the measured and the predicted model outputs are in very good agreement during the model validation procedure. From the observation, the model predicted values are quite accurate compared to the measured values with maximum error of $0.97 \%$.

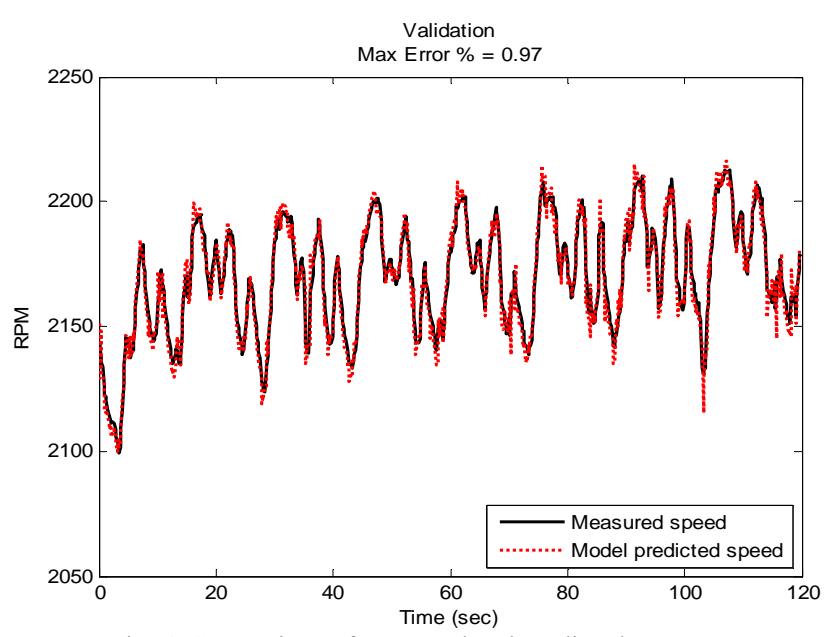

Fig. 6. Comparison of measured and predicted outputs.

The modeling error between the system output (measured speed value) and the predicted model output is shown in Fig. 7. Observation on the error values a show that, on average, the error values is about $\pm 8 \mathrm{rpm}$. To further asses the adequacy of the prediction models, the estimated standard error of the regression $(\hat{\sigma})$ and the $R^{2}$ of the model is calculated where:

$$
\begin{aligned}
\hat{\sigma} & =\sqrt{\frac{\text { sum of squared errors }}{\text { degree of freedom }}} \\
R^{2} & =1-\frac{\text { sum of squared errors }}{\sum\left(y_{i}-\bar{y}\right)^{2}}
\end{aligned}
$$

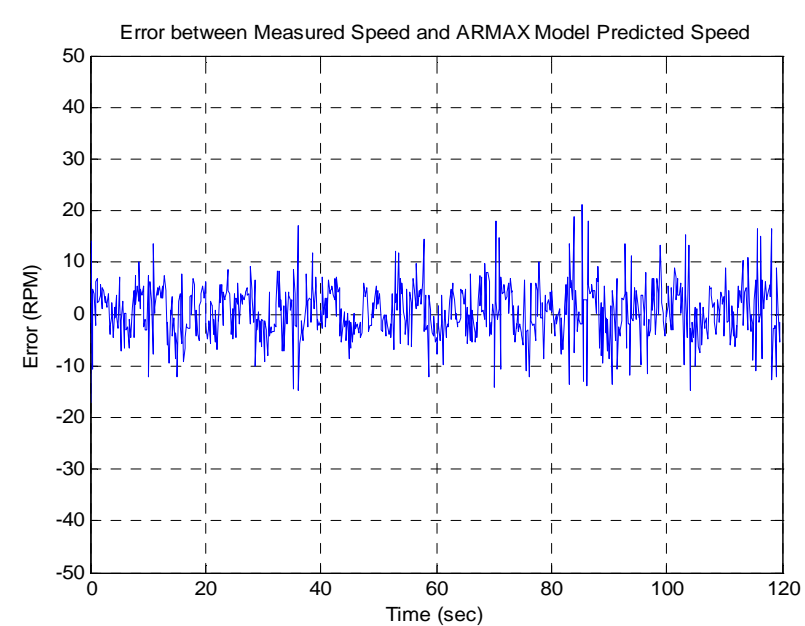

Fig. 7. Modeling error between measured value and model predicted value.

TABLE IV: STANDARD ERROR $(\hat{\sigma})$ AND $R^{2}$ FOR THE PREDICTED MODEL

\begin{tabular}{lcc}
\hline \hline Model $\backslash$ Parameter & $\hat{\sigma}$ & $R^{2}$ \\
\hline ARMAX & $5.4 \mathrm{rpm}$ & 0.94 \\
\hline \hline
\end{tabular}


Table IV shows the model fitting ARMAX model derived in this work. It can be clearly seen that the standard error of regression value is just about $6 \mathrm{rpm}$. This shows how well the fitted equation fits the sample data. Also, the value of $R^{2}$ which is closer to 1 indicates a goodness of fit of the estimation equation.

Thus, the dynamic mathematical model derived in this work is acceptable and valid. The model is an approximation of an automotive diesel engine fuelled with palm oil biodiesel around the speed range around $2100 \mathrm{rpm}$.

\section{CONCLUSION}

In this work, the development of stochastic models of an automotive diesel engine fuel with palm oil biodiesel has been presented. The model was successfully identified using black-box modeling technique. The mathematical model developed in this paper present an analysis and simulation tools of the engine dynamic system that forms the foundation for a systematic approach to the analysis, simulation and synthesis of the automotive palm oil biodiesel engine control systems. Currently, a nonlinear model of the plant is being developed. For future work, a speed controller for this palm oil biodiesel engine will be considered.

\section{ACKNOWLEDGEMENTS}

This work was conducted in the Thermodynamic and Process Control Laboratories of School of Manufacturing Engineering, University Malaysia Perlis. The authors would like to thank the individuals who were involved in making this work possible.

\section{REFERENCES}

[1] The National Biofuel Policy. Mionistry of Plantation Industries and Commodities. 21 March 2006

[2] T. M. I. Mahlia, M. Z. Abdulmuin, T. M. I. Alamsyah, and D. Mukhlishien, "An alternative energy source from palm wastes industry for malaysia and indonesia", Energy Conversion and Management, vol. 42, issue 18, pp. 2109-2118, December 2001.

[3] T. M. I. Mahlia, M. Z. Abdulmuin, T. M. I. Alamsyah, and D. Mukhlishien, "Dynamic modeling and simulation of a palm wastes boiler", Renewable Energy, vol. 28, issue 8, pp. 1235-1256, July 2003.

[4] H. Masjuki, M. Z. Abdulmuin, and Sii H. S., "Indirect diesel engine operation on palm oil methyl esters and its emulsions", Proc. IMechE, Vol. 211, Part D, J. Of Automobile Eng. 1997, pp. 291-299.

[5] M. Balat and H. Balat, "A critical review of bio-diesel as a vehicular fuel". Energy Conversion and Management., 49 (2008), pp. 27272741.

[6] Demirbas, "Importance of biodiesel as transportation fuel". Energy Policy, 35 (2007), pp. 4661-4670.

[7] A. K. Agrawal, "Biofuels (alcohols and biodiesel) applications as fuels for internal combustion engines". Progress in Energy and Combustion Science, 33(2007), pp. 233-271.
[8] Choo Y. M., Ma A. N., Chan K. W., and Yusof B., "Palm diesel: an option for greenhouse gas mitigation in the energy sector". J. Oil Palm Research, 17 (2005), pp. 47-52.

[9] S. Mekhilef, S. Siga, and R.Saidur, "A review on palm oil biodiesel as a source of renewable fuel", Renewable and Sustainable Energy Reviews, 15(2011) pp. 1937-1949

[10] R. Adnan, I. M. Azree, and A. Zulkifli., "Power performance and exhuast gas analyses of palm oil and used cooking oil methyl ester as fuel for diesel engine". ICCBT 2008, pp. 103-108.

[11] Oguntola J. A., Ezra A. A., Nurudeen O.A., and Salam O. I., "Power and Torque Characterictics of diesel engine fuelled by palm-kernel oil biodiesel", Leonardo Journal of Science, 14 (2009), pp. 66-73.

[12] Prateepchaikul G. and Apichato T., "Palm oil as fuel for agriculture diesel engine: Comparative testing against diesel oil". Songklanakarin J. Sci. Technol., 25(3) 2003, pp. 317-326.

[13] K. Kalyani Radha, S. Naga Sarada, Dr. K. Rajagopal, "Alternative fuels for a single cylinder direct injection diesel engine", International Conference on Emerging Trends in Engineering and Technology (ICETET 2008), pp. 1083-1088.

[14] Moron-Villarreyes, J. A., Soldi, C., Amorim, A.M., Pizzolatti, M.G., Mendonca Jr., A.P., D’Oca, MGM, Diesel/biodiesel proportion for by-compression ignition engines. Fuel 86 (2007), pp. 1977-1982.

[15] Ganapathy, T., Murugesan, K., and Gakkhar, R.P., "Performance optimization of Jatropha biodiesel engine model using Taguchi approach”. J. Applied Energy. 86 (2009), pp. 2476-2486.

[16] Ramadhas A. S., Jayaraj S., and Muraleedharan C., "Theoritical modeling and experimental studies on biodiesel-fuelled engine". $J$. Renewable Energy. 31 (2006), pp. 1813-1826.

[17] M. Md. Ramli and A.S. Morris. "A Non-linear Mathematical Engine Model for the Development of Dynamic Engine Control". University of Sheffield, pp. 90-94.

[18] P.E. Wellstead, and M.B. Zarrop, Self-Tuning Systems: Control and Signal Processing. Chicester, John Wiley \& Sons, 1991.

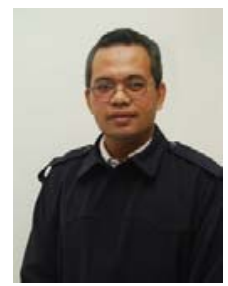

Azuwir Mohd Nor received his BSc degree in Electrical Engineering from University of WisconsinMadison, USA and Master's degree in Information Technology from Universiti Utara Malaysia, Kedah, Malaysia in 1992 and 2002, respectively. $\mathrm{He}$ is currently pursuing his Ph.D. degree at Universiti Malaysia Perlis, Malaysia. His main research areas are system identification, control theory, digital control systems and self-tuning control.

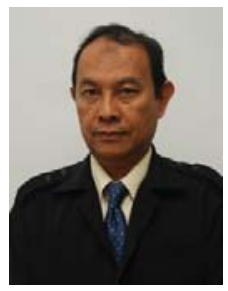

Mohd Zaki Abdulmuin was born in Malaysia in 1950. He obtained $\mathrm{PhD}$ in modeling and control from University of Malaya in 1989, and worked for 25 years in the same university. He has published more than 70 research papers. Currently he is on contract with University Malaysia Perlis. Research interests include Physical and black-box modeling and adaptive control.

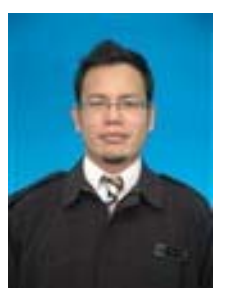

Abdul Hamid Adom received his $\mathrm{PhD}$ in Artificial Intelligence in 2001 and MSc in Modern Control \& Instrumentation Systems in 1996, and is currently an Associate Professor at Universiti Malaysia Perlis. Among his research interests are Artificial Human Sensing and Robotics as well as Artificial Intelligence. 